\title{
Analysis on Steady-State Operation and Heat Loss of Chinese Integrated Pressurized Water Reactor
}

\author{
Zhang Fan, Lu Dao-Gang, Sui Dan-Ting, Guo Chao, and Yuan Bo \\ School of Nuclear Science and Engineering, North China Electric Power University, Beijing 102206, China \\ Correspondence should be addressed to Zhang Fan; hdhxyzf@126.com
}

Received 8 June 2014; Revised 19 August 2014; Accepted 20 August 2014; Published 1 September 2014

Academic Editor: Borut Mavko

Copyright (C) 2014 Zhang Fan et al. This is an open access article distributed under the Creative Commons Attribution License, which permits unrestricted use, distribution, and reproduction in any medium, provided the original work is properly cited.

\begin{abstract}
Chinese integrated pressurized water reactor (CIPWR) has compact configuration and high inherent safety, which is appropriate for nuclear power plants of small and medium scale. Heat balance model has been adopted widely in thermal power calibration of PWRs because of its advantage of accuracy. In this paper, a package based on FORTRAN language is developed and added into RELAP5 to calculate the heat loss value needed in heat balance analysis. The steady-state operation of CIPWR is modelled correctly by RELAP5. The heat loss of CIPWR is calculated by the package, and the comparison of the main values of parameters needed in the heat loss calculation between RELAP5 and the package has been done. It shows that the package has high calculation accuracy and can be applied in reactor design and monitoring.
\end{abstract}

\section{Introduction}

Reactor Excursion and Leak Analysis Program (RELAP5) is a reactor analysis program developed by Idaho National Engineering Laboratory (INEL), approved by Nuclear Regulatory Commission (NRC) for engineering review of thermal hydraulic calculation of PWRs [1]. RELAP5 has been generally applied to reactor design and safety analysis of PWRs, which is convenient for users and has high calculation efficiency. With the increasing study requirements, lots of routine packages are added to RELAP5 by users to meet their own study needs.

To make reactor operate more safely and economically, the accurate calibration of real thermal power is important for design, analysis, and monitoring of the reactor, which has been applied in PWRs currently [2]. The heat balance model has been adopted widely in thermal power calibration with advantage of accuracy. The heat loss (or increase) from other heat sources (except reactor core) in primary loop is needed in the heat balance calculation, which has to be obtained from operating experience sometimes. A package based on FORTRAN language is developed and added into RELAP5 in this study, which makes it have the ability to calculate the heat loss in heat balance calculation.

Integral pressurized water reactor (IPWR) is one of the hot issues in the field of small-size nuclear systems, which has high inherent safety. The structure of IPWR is more compact for the reason of the less use of pipes. The characteristic of small size makes IPWR more easily used in different conditions than other reactors, such as ships and remote places. There are various IPWR designs in the world with the same characteristic [3, 4]; that is, all primary-loop components are arranged inside the pressure vessel to eliminate or minimize the possibility of loss of coolant accident (LOCA). IRIS [5] reactor developed by USA, System-Integrated Modular Advanced Reactor (SMART) [6] developed by the Korea Atomic Energy Research Institute (KAERI), and CAREM-25 [7] developed by Argentina are the typical IPWR designs with coolant pumps. The multiapplication small light water reactor (MASLWR) [8] without any pumps uses natural circulation in both steady and transient operations. There are several different concepts of IPWR proposed by Nuclear Power Institute of China $[9,10]$. One of these designs of IPWR with coolant pumps is our study object, which is called CIPWR in this paper.

Our study aims at evaluating the performance of CIPWR in stable and transient operations. In this paper, RELAP5/ MODE3.4 is used to model the stable condition of CIPWR and calculate the heat loss needed in heat balance analysis with the package we developed. The series of transient accidents of CIPWR will be studied in the future. 


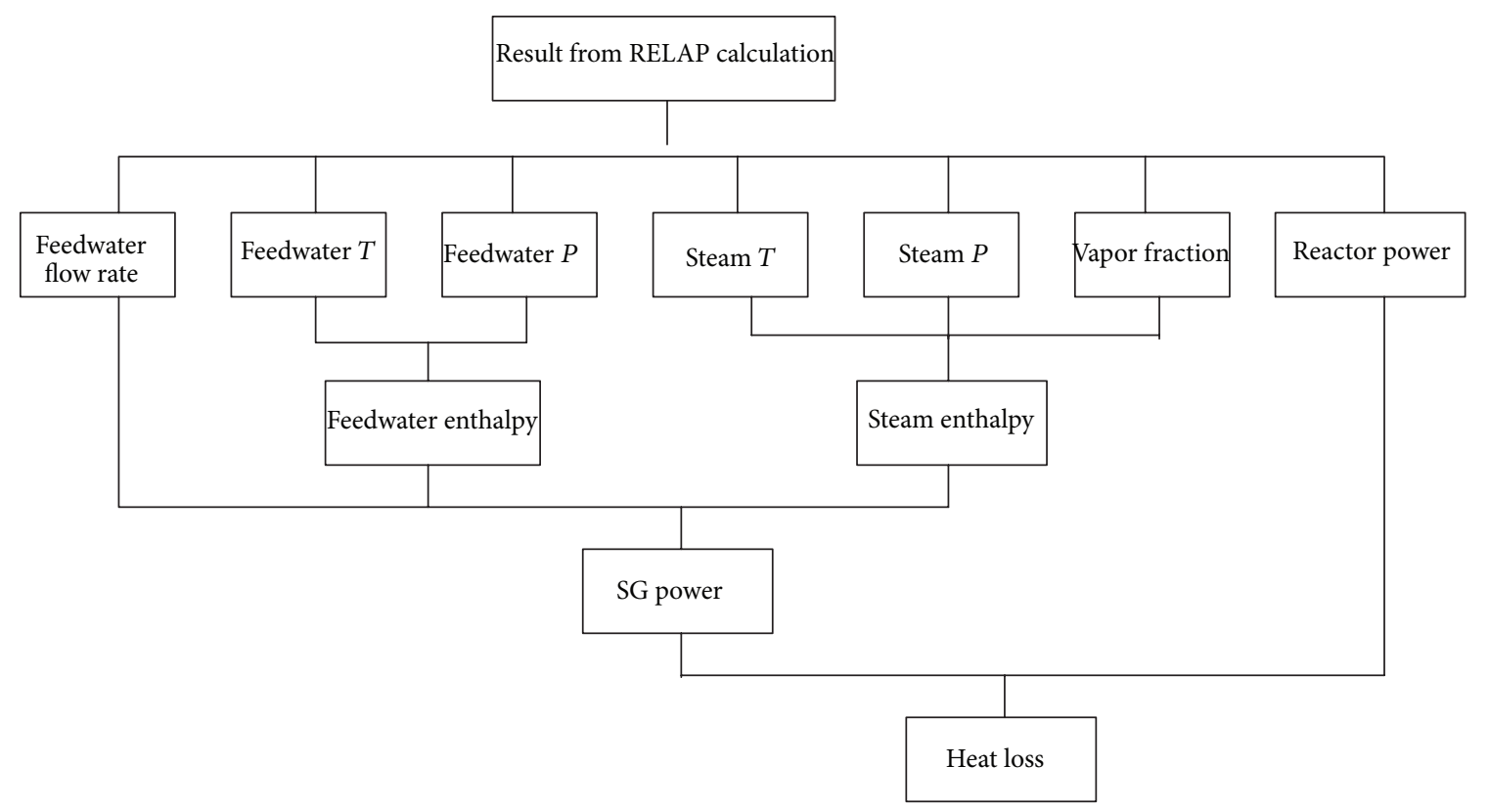

FIgURE 1: Structure of the heat loss package.

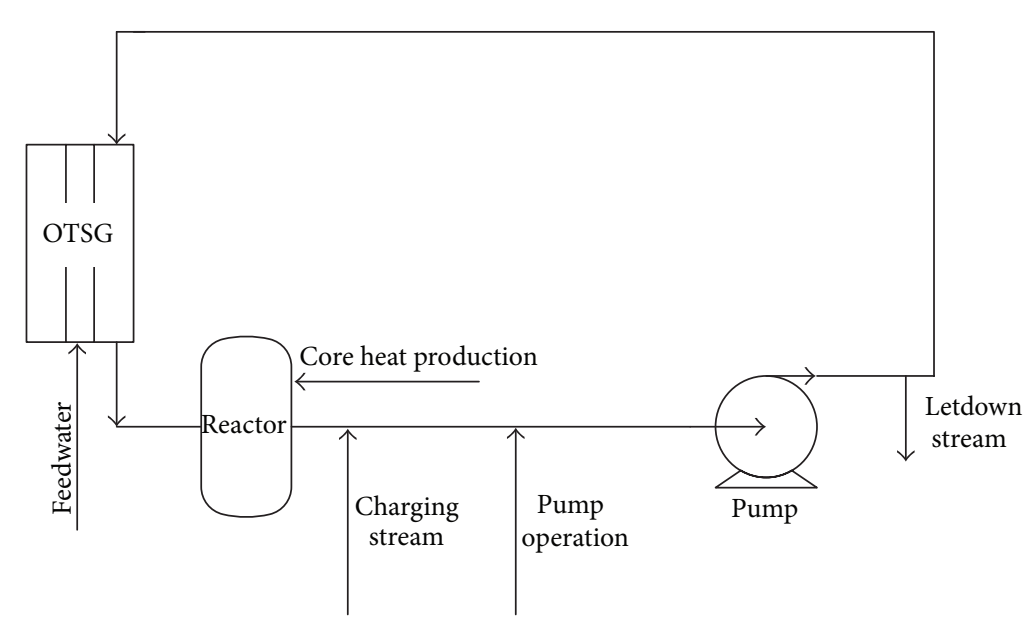

Figure 2: Heat balance principle diagram of CIPWR.

\section{Theoretical Modelling}

2.1. Heat Loss Calculation Package. The package added to RELAP5 is used to calculate the heat loss in heat balance analysis. All the input values in the package can be obtained from the calculation result of steady condition by RELAP5, such as the value of temperature, pressure, and vapour fraction. Figure 1 shows the flow chart of the package.

2.1.1. The Principle of Heat Balance. Heat balance method is based on the steam generator approximation enthalpy balance [11]; that is, the enthalpy increase of feedwater is the main part of the thermal power. The thermal power can be calculated through the enthalpy difference between the steam and feedwater in the second loop, counting the internal heat loss at the same time.
As is shown in Figure 2, there are several ways for CIPWR primary system to obtain or lose heat (for other PWRs, the pressurizer electrical heating should be taken into consideration). The heat increase consists of core heat production, the heat brought in by charging stream, and heat production during the pump operation. The heat decrease consists of heat dissipation of components and the heat taken by letdown stream. The feedwater in the second loop exchanges heat with primary loop by $U$ tubes. The heat balance principle of the CIPWR can be described by

$$
W_{R}=W_{\mathrm{SG}}-W_{\Delta \mathrm{Pr}},
$$

where the $W_{R}(\mathrm{MW})$ is the core thermal power, which can be obtained from the RELAP5 calculation result and $W_{\mathrm{SG}}(\mathrm{MW})$ is the steam generator power obtained from the primary loop, which can be obtained by the package. $W_{\Delta \operatorname{Pr}}(\mathrm{MW})$ is the 
heat loss, which is the sum of thermal power coolant obtained from other heat sources except core and lost because of the heat dissipation of components and pipes. The heat loss $W_{\Delta \mathrm{Pr}}$ (MW) is the calculation result of the package.

In the second loop, unsaturated feedwater with the mass flow rate $Q_{e}(\mathrm{~kg} / \mathrm{s})$ and specific enthalpy $H_{e}$ flows through the heat transfer tube and convects with the first side of steam generator and turns to the steam with the specific enthalpy $H_{v}(\mathrm{~kJ} / \mathrm{kg})$. Equation (2) can be used to calculate the steam generator power:

$$
W_{\mathrm{SG}}=\left(H_{v}-H_{e}\right) Q_{e}
$$

where $H_{v}$ is the steam enthalpy of steam in the generator export, $H_{e}(\mathrm{~kJ} / \mathrm{kg})$ is the feedwater enthalpy, and $Q_{e}(\mathrm{~kg} / \mathrm{s})$ is the flow rate of feedwater.

2.1.2. Thermodynamic Properties Subroutine. The enthalpy of water and steam included in the heat balance calculation can be computed by the thermodynamic properties subroutine according to IAPWS-IF97 [12] (IAPWS Industrial Formulation 1997 for the Thermodynamic Properties of Water and Steam). IAPWS-IF97 replaced the previous industrial formulation IFC-67 [13] for industrial use for its advantage of calculation with speed and accuracy.

The range of IAPWS-IF97 has five subareas, each of which has a basic equation that can be used to calculate the water and steam properties by derivation. As one of the thermophysical properties, enthalpy can be obtained directly from the pressure and temperature values by the basic equations except region 3. The feedwater in the entrance of steam generator is unsaturated water belonging to region 1, whose thermophysical properties can be computed by (3). This equation is a fundamental equation for the specific Gibbs free energy $g$ expressed in dimensionless form:

$$
\frac{g(p, T)}{R T}=\gamma(\pi, \tau)=\sum_{i=1}^{34} n_{i}(7.1-\pi)^{I_{i}}(\tau-1.222)^{J_{i}},
$$

where $\pi=p / p^{*}$ and $\tau=T^{*} / T$ with $p^{*}=16.53 \mathrm{MPa}, T^{*}=$ $1386 \mathrm{~K}$, and $R=0.461526 \mathrm{~kJ} \mathrm{~kg}^{-1} \mathrm{~K}^{-1}$ and $p(\mathrm{MPa})$ and $T(\mathrm{~K})$ are pressure and temperature value of the unsaturated water. The coefficients $n_{i}$ and exponents $I_{i}$ and $J_{i}$ are given in the IAPWS-IF97.

The enthalpy of feedwater can be computed by

$$
\begin{aligned}
H_{e} & =g-T\left(\frac{\partial g}{\partial T}\right)_{p} \\
& =\tau R T \times \sum_{i=1}^{34} n_{i}(7.1-\pi)^{I_{i}} J_{i}(\tau-1.222)^{J_{i}-1} .
\end{aligned}
$$

The steam in the export of steam generator loop is wet saturated steam consisting of saturated steam and saturated water with different enthalpy. The total enthalpy of steam can be calculated according to the vapor fraction $x$ as

$$
H_{v}=x H_{v s}+(1-x) H_{l s} \text {, }
$$

TABLE 1: Comparison of calculation results between package subroutine and IAPWS-IF97.

\begin{tabular}{lccc}
\hline Region & Parameters & Given by & $h\left(\mathrm{~kJ} \mathrm{~kg}^{-1}\right)$ \\
\hline \multirow{2}{*}{ Region 1} & $T=300 \mathrm{~K}$ & IF97 & 115.331273 \\
& $P=3 \mathrm{MPa}$ & Package & 115.33127302 \\
& $T=300 \mathrm{~K}$ & IF97 & 184.142828 \\
& $P=80 \mathrm{MPa}$ & Package & 184.14282773 \\
\hline \multirow{2}{*}{ Region 2 } & $P=300 \mathrm{~K}$ & IF97 & 2549.91145 \\
& $T=0.0035 \mathrm{MPa}$ & Package & 2549.9114508 \\
& $P=2000 \mathrm{~K}$ & IF97 & 6571.22604 \\
& $P=30 \mathrm{MPa}$ & Package & 6571.2260386 \\
\hline
\end{tabular}

where $H_{l s}(\mathrm{~kJ} / \mathrm{kg})$ is the saturated water enthalpy, which can be calculated by (4). $H_{v s}$ is the saturated steam enthalpy belonging to region 2 , which can be calculated by (6). This equation is a fundamental equation for the specific Gibbs free energy $g$ expressed in dimensionless form:

$$
\frac{g(p, T)}{R T}=\gamma(\pi, \tau)=\ln \pi+\sum_{i=1}^{9} n_{i}^{o} \tau^{J_{i}^{o}}+\sum_{i=1}^{43} n_{i} \pi^{I_{i}}(\tau-0.5)^{J_{i}} .
$$

The enthalpy of saturated steam $H_{v s}(\mathrm{~kJ} / \mathrm{kg})$ can be computed by

$$
\begin{aligned}
H_{v s} & =g-T\left(\frac{\partial g}{\partial T}\right)_{p} \\
& =\tau R T \times\left\{\frac{1}{\pi}+\sum_{i=1}^{43} n_{i} I_{i} \pi^{I_{i}-1}(\tau-0.5)^{J_{i}}\right\},
\end{aligned}
$$

where $\pi=p / p^{*}$ and $\tau=T^{*} / T$ with $p^{*}=1 \mathrm{MPa}, T^{*}=540 \mathrm{~K}$, and $R=0.461526 \mathrm{~kJ} \mathrm{~kg}^{-1} \mathrm{~K}^{-1}$ and $p(\mathrm{MPa})$ and $T(\mathrm{~K})$ are pressure and temperature value of the unsaturated water. The coefficients $n_{i}^{o}, J_{i}^{o}, n_{i}, I_{i}$, and $J_{i}$ are given in the IAPWS-IF97.

As shown in Table 1, the validation of this subroutine has been done by comparing it with the value given in IAPWSIF97.

2.2. Modelling of Steady Operation of CIPWR. The whole reactor system can be modelled by different modules of RELAP5, which contains hydrodynamic components, branches, heat structures, reactor kinetics, control system, and so on. Hydrodynamic components consist of the parts where the fluid flows through, such as pipes, annulus, valves, pumps, and time-dependent volumes. Heat structures simulate the heat transfer in the system by setting the thermal conductivity and heat capacity of materials. Control system can set the change with time of physical quantities and trips and also can be used in self-initialization. Reactor kinetics consist of multigroup neutron transport model and point reactor model, which calculate the power of reactor by setting the initial power and reactivity feedback coefficient of various influent factors.

Figure 3 shows the sketch of CIPWR with two loops with coolant pumps. Once-through steam generators (OTSG) are adopted for the advantage that the configuration is compact 


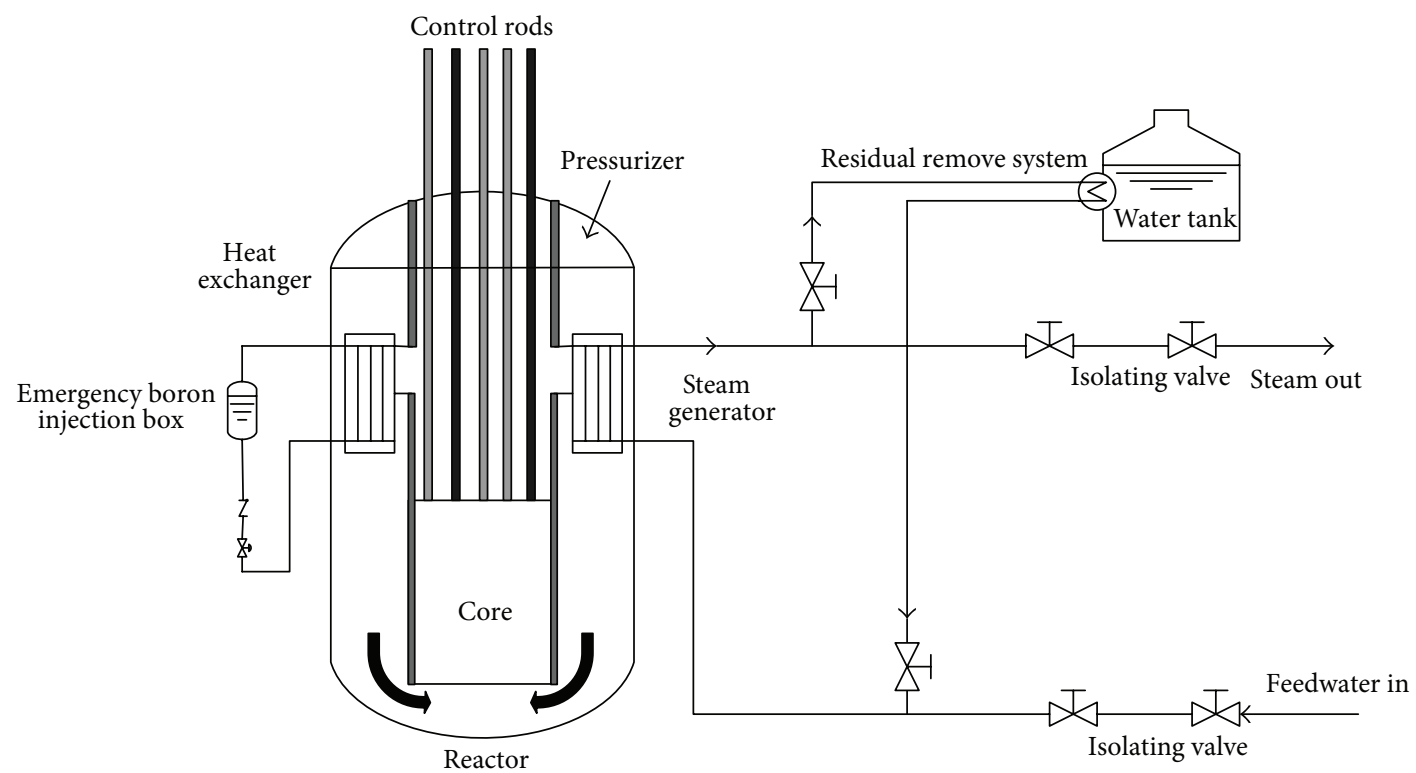

Figure 3: Sketch of CIPWR.

enough to enable their location in the pressure vessel. OTSGs are arranged above the reactor core for the better natural circulation in case of SBO accident. The upper pressure vessel space acts as pressurizer in CIPWR, which eliminates lots of pipes effectively. These unique designs of CIPWR make it a compact PWR and reduce the risk of some accidents such as LOCA effectively.

Figure 4 shows the node map of CIPWR based on RELAP5/MODE3.4. Reactor kinetics chose point reactor model, and the reactor power is $100 \mathrm{MW}$. Average channel model is adopted in modelling reactor core, which can meet the requirements of steady-state calculation. Although the real arrangement in core should be modelled to compute more accurately, lots of fuel elements nodes tremendously increase computation time, which is not necessary in this study. As is shown in Figure 5, the core channel is modelled by a pipe and a heat structure with three materials, which are uranium dioxide for core fuel, helium for the gap, and zirconium alloy for fuel cladding from the inside out.

OTSG has high power density and can be adjusted rapidly, which makes it conventionally applied in IPWR. Figure 6 shows the node map of bushing OTSG CIPWR used. The feedwater in second side obtains heat by convection with first side of OTSG and turns to the steam along the flow channel. The design of two pipes in the primary loop makes heat transfer effective and structure compact. The material of heat structure between two sides of OTSG is Inconel $600 \mathrm{MA}$, which is widely used for steam generator tubes.

\section{Calculation Result}

3.1. Steady Operation of CIPWR Modelled by RELAP5. Steady state of CIPWR has been modelled by RELAP5. Figure 8 shows the pressure values of reactor core, feedwater in the entrance of OTSG, steam in the export of OTSG, and the

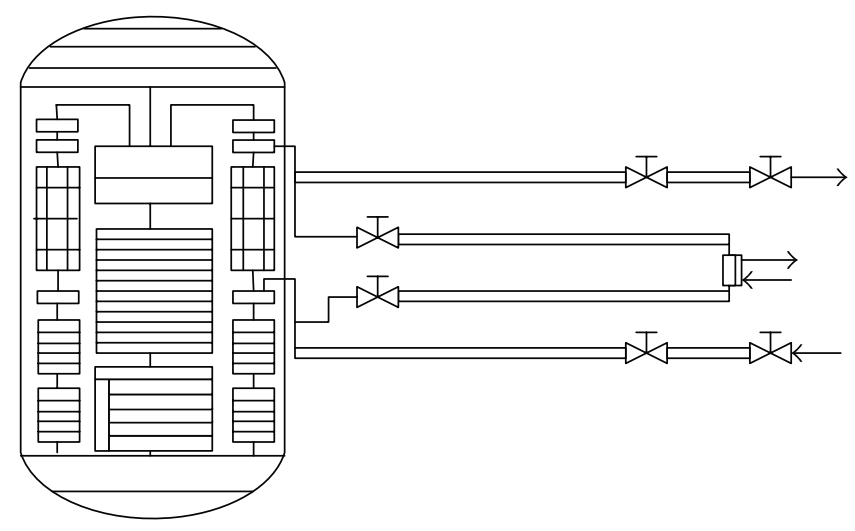

FIgURE 4: Node map of CIPWR.

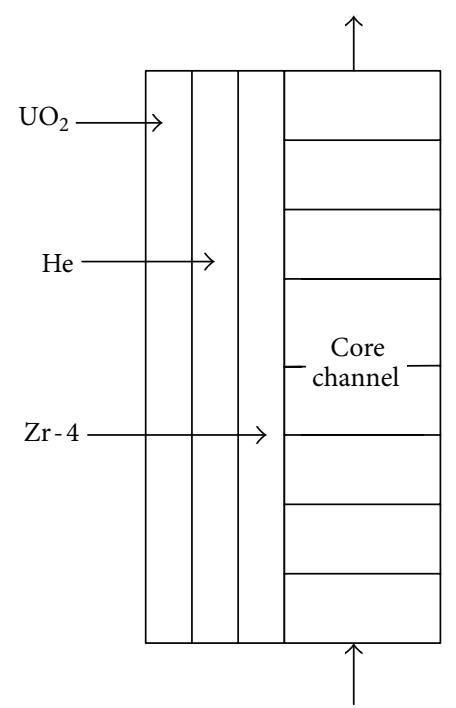

FIGURE 5: Sketch of core materials. 


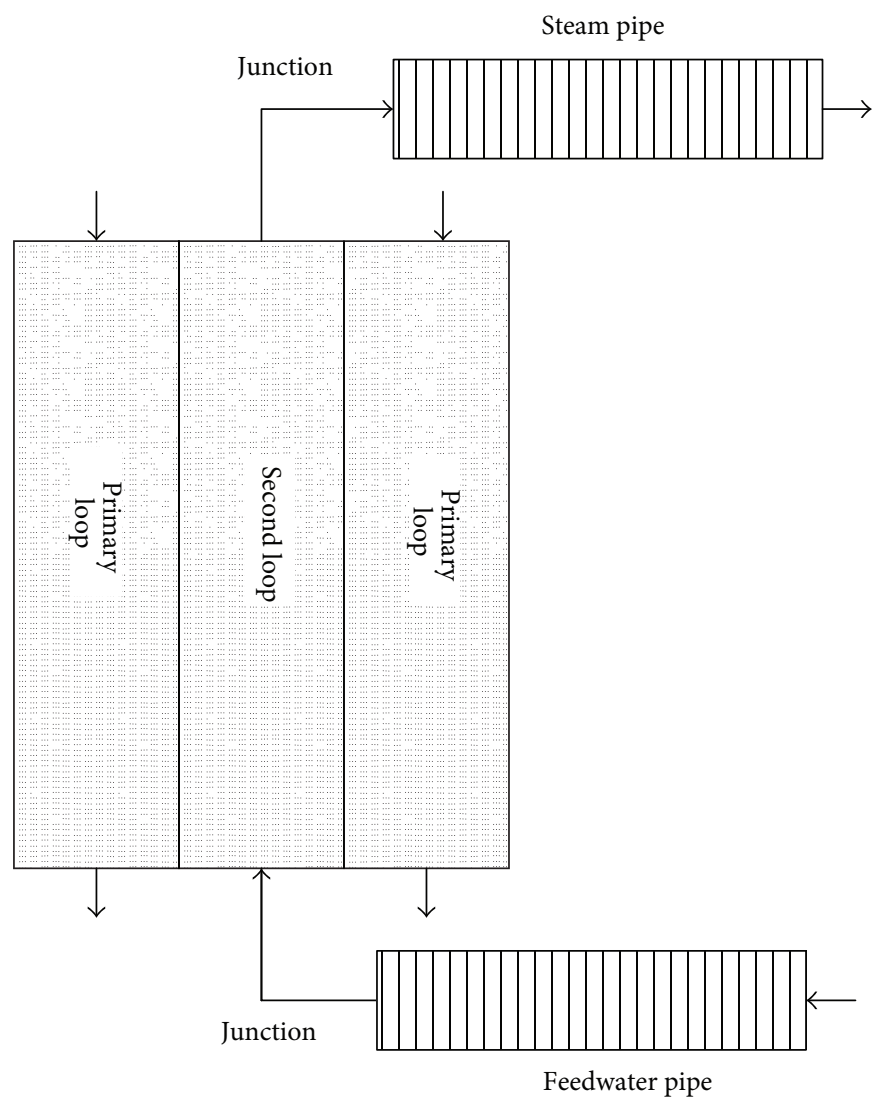

Figure 6: Node map of OTSG.

equivalent pressurizer in the upper pressure vessel space. As shown in Figure 7, the pressure values are nearly stable during the operation; that is, the pressure value of core remains $7.1127 \mathrm{MPa}$, the pressure value of upper plenum remains 7.0989 MPa, the pressure value of low plenum remains $7.1216 \mathrm{MPa}$, and the pressure value of the equivalent pressurizer remains $7.07127 \mathrm{MPa}$, which shows that the upper pressure vessel space can act as the pressurizer. The distribution of pressure is in agreement with the design pressure value (7.063 MPa) of pressurizer.

Figure 8 shows the temperature values of reactor core, feedwater in the entrance of OTSG, steam in the export of OTSG, and the equivalent pressurizer in the upper pressure vessel space. As shown in the figure, the temperature values reach steady state after about 10 seconds and are consistent with the trend of heat transfer.

Table 2 shows calculation values of pressure and temperature in different positions modelled by RELAP5.

3.2. The Calculation of Heat Loss. When steady-state operation finished, the heat loss calculation package started, using the value in the RELAP calculation result. The calculation result is shown in Table 3; the heat loss of CIPWR is $1.3454 \mathrm{MW}$.

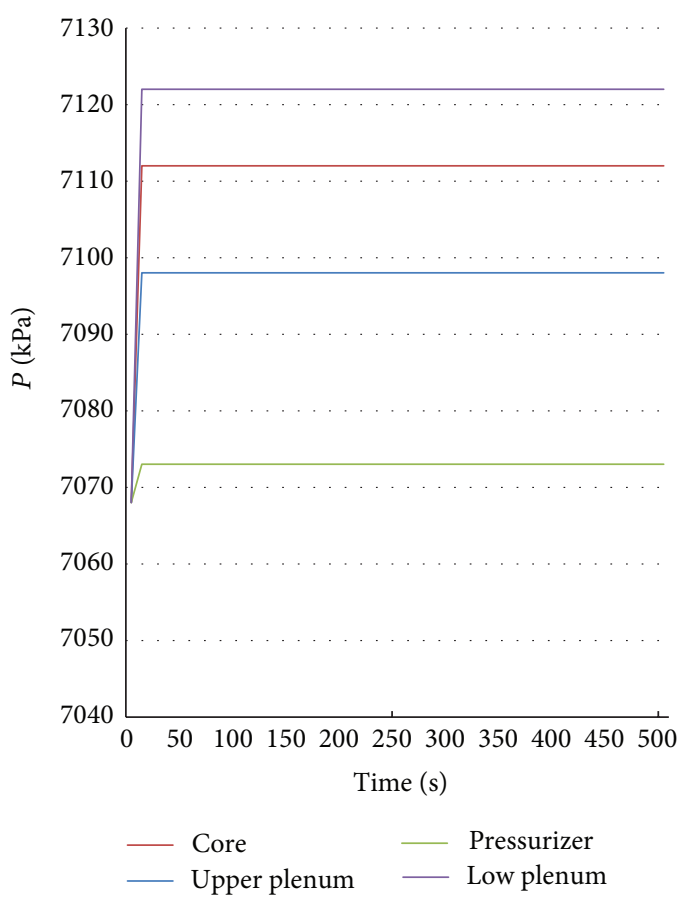

FIGURE 7: Pressure of reactor core, upper plenum, low plenum, steam, and pressurizer in steady state. 


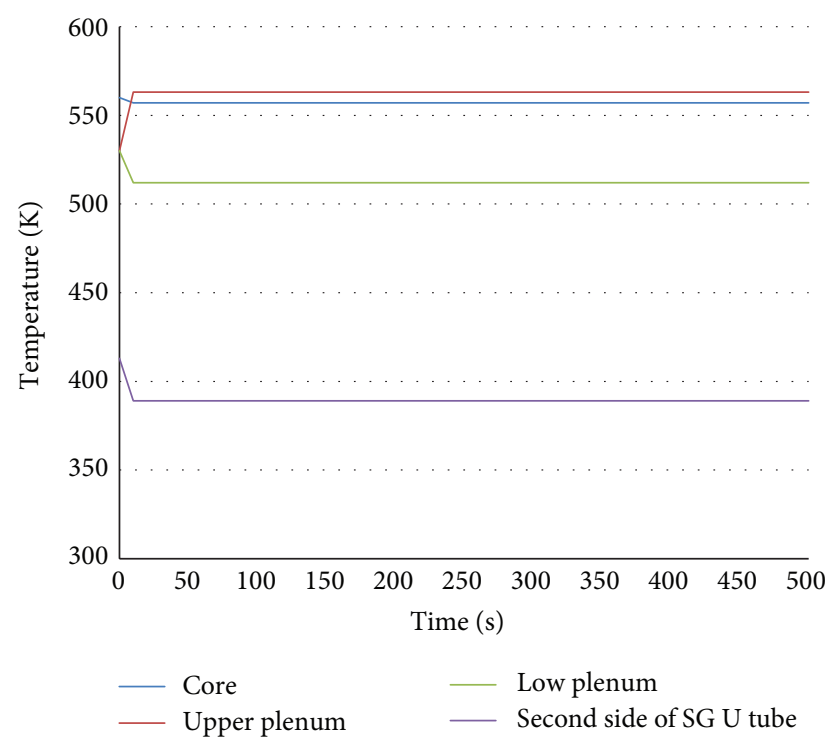

FIGURE 8: Temperature of reactor core, upper plenum, low plenum, steam, and second side of SG U tube in steady state.

TABLE 2: RELAP5 calculation values of pressure and temperature in different positions.

\begin{tabular}{lcc}
\hline Parameter & Position & Values \\
\hline & Core & 7.1127 \\
& Upper plenum & 7.0989 \\
Pressure & Low plenum & 7.1216 \\
$(\mathrm{MPa})$ & Pressurizer & 7.07127 \\
& SG feedwater & $3.0 \mathrm{MPa}$ \\
& SG steam & $2.943 \mathrm{MPa}$ \\
\hline & Core & 0.9667 \\
Temperature & Upper plenum & 557.59 \\
$(\mathrm{~K})$ & Low plenum & 515.17 \\
& SG primary side & 547.92 \\
& SG feedwater & 423.15 \\
& SG steam & 505.93 \\
\hline
\end{tabular}

As is shown in Table 4, all of the errors of the main values of parameters needed in the heat loss calculation between RELAP5 and the package are less than $0.3 \%$, which means that the reasonable calculation result can be obtained by the heat loss package.

\section{Conclusions}

The comparison between the simulated value and design value shows that the steady state of CIPWR has been modelled by RELAP5 correctly. According to the distribution of simulated values of pressure in primary loop, the upper pressure vessel space can act as pressurizer practically with the advantage of eliminating lots of pipes which reduces the risk of some accidents effectively.
TABLE 3: Values of heat loss calculation.

\begin{tabular}{lcc}
\hline Belong to & Parameters & Values \\
\hline & Feedwater & $423.15 \mathrm{~K}$ \\
& temperature & $3.0 \mathrm{MPa}$ \\
& Feedwater pressure & $506.05 \mathrm{~K}$ \\
RELAP5 & Steam temperature & $2.943 \mathrm{MPa}$ \\
& Steam pressure & 0.9667 \\
& Vapor fraction & $96.58 \mathrm{MW}$ \\
& Reactor power & $43.9 \mathrm{~kg} / \mathrm{s}$ \\
\hline \multirow{3}{*}{ Heat loss } & Feedwater flow rate & $633.813 \mathrm{~kJ} / \mathrm{kg}$ \\
calculation & Feedwater enthalpy & $2802.974 \mathrm{~kJ} / \mathrm{kg}$ \\
package & Steam enthalpy & $95.226 \mathrm{MW}$ \\
& OTSG power & $1.354 \mathrm{MW}$ \\
\hline
\end{tabular}

TABLE 4: Difference and error of calculation results between RELAP5 and package.

\begin{tabular}{lcccc}
\hline Parameter & $\begin{array}{c}\text { RELAP5 } \\
\text { calculation } \\
\text { results }\end{array}$ & $\begin{array}{c}\text { Package } \\
\text { calculation } \\
\text { results }\end{array}$ & Difference & Error (\%) \\
\hline $\begin{array}{l}\text { Feedwater } \\
\text { enthalpy } \\
(\mathrm{kJ} / \mathrm{kg})\end{array}$ & 633.602 & 633.813 & 0.211 & 0.0333 \\
$\begin{array}{l}\text { Steam } \\
\text { enthalpy } \\
(\mathrm{kJ} / \mathrm{kg})\end{array}$ & 2798.343 & 2802.974 & 4.631 & 0.1655 \\
$\begin{array}{l}\text { OTSG } \\
\text { Power (MW) }\end{array}$ & 95.032 & 95.226 & 0.194 & 0.2041 \\
$\begin{array}{l}\text { Heat } \\
\text { Loss (MW) }\end{array}$ & 1.548 & 1.354 & 0.194 & - \\
\hline
\end{tabular}

The heat loss calculation package which is added to RELAP5 was developed based on heat balance method. The comparison of the main values needed in the heat loss calculation between RELAP5 and the package shows that the heat loss package can be applied in reactor design and monitoring. Further study will aim at calculating the series of transient accidents of CIPWR based on the steady state by RELAP5.

\section{Conflict of Interests}

The authors declare that there is no conflict of interests regarding the publication of this paper.

\section{References}

[1] Nuclear Safety Analysis Division, "RELAPS/MOD3.3 Code Manual Volume I: Code Structure, System models, and Solution Methods," Information Systems Laboratories, December 2001.

[2] Y. Guo dong and P. Zefei, "The analysis of Qinshan second nuclear power plant power calibration method," in Proceedings of the 12th Reactor Numerical Calculation and Particle Transport Academic Conference, Anhui, China, 2008. 
[3] "Innovative Small and Medium Sized Reactors: Design features, safety approaches and R\&D trends," IAEA-TECDOC-1451, 2005.

[4] N. Cavlina and D. Grgie, "Evaluation of accident sequences in IRIS relevant for revising the need for relocation and evacuation measures unique to Npps for innovative SMRs," in Proceedings of the IAEA CRP RCM Meeting, Vienna, Austria, November 2005.

[5] A. C. O. Barroso and B. D. Baptista, "Refining the design and analysis of the IRIS pressurizer," in Proceedings of the 5th International Conference on Nuclear Option in Countries with Small and Medium Electricity Grids, Dubrovnik, Croatia, 2004.

[6] T. W. Kim, K. B. Park, K. H. Jeong, G. M. Lee, and S. Choi, "Dynamic characteristics of the integral reactor SMART," Journal of the Korean Nuclear Society, vol. 33, no. 1, pp. 111-120, 2001.

[7] C. P. Marcel, D. F. Delmastro, H. Furci, and V. P. Masson, "Stability of self-pressurized, natural circulation, low thermodynamic quality, nuclear reactors: phenomenology involved in the thermal-hydraulics of the CAREM-25 reactor," Nuclear Engineering and Design, vol. 254, pp. 218-227, 2013.

[8] J. N. Reyes, J. Groome, B. G. Woods et al., "Testing of the multiapplication small light water reactor (MASLWR) passive safety systems," Nuclear Engineering and Design, vol. 237, no. 18, pp. 1999-2005, 2007.

[9] Q. Zhong, "Research and design of China integral reactor plant innovative containment," Nuclear Power Engineering, vol. 27, no. 6, pp. 91-98, 2006.

[10] C. Shulin, L. Guiiun, Z. Senru et al., "Inherent safe UZrHx power reaetor INSURE-100 preliminary research," Nuclear Power Engineering, vol. 15, pp. 289-293, 1994.

[11] F. Zhang, D.-G. Lu, D.-T. Sui, B. Yuan, and C. Guo, "Preliminary development of thermal power calculation code $\mathrm{H}$-power for a supercritical water reactor," Science and Technology of Nuclear Installations, vol. 2014, Article ID 279092, 10 pages, 2014.

[12] The International Association for the Properties of Water and Steam, "Release on the IAPWS Industrial Formulation 1997 for the Thermodynamic Properties of Water and Steam, Germany, 1997".

[13] The 1967 IFC Formulation for Industrial Use, Unrestricted Publication Allowed in All Countries. 


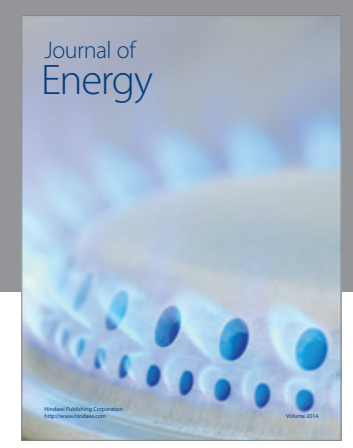

Journal of

Industrial Engineering
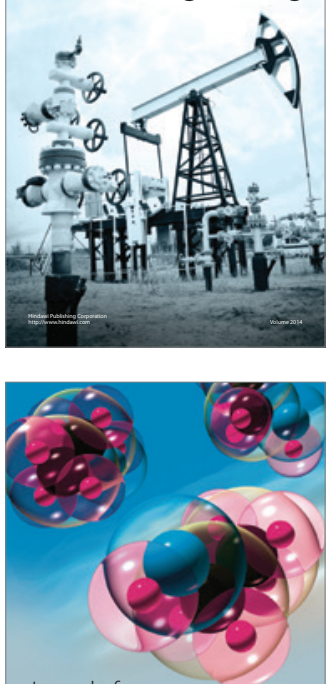

Fuels
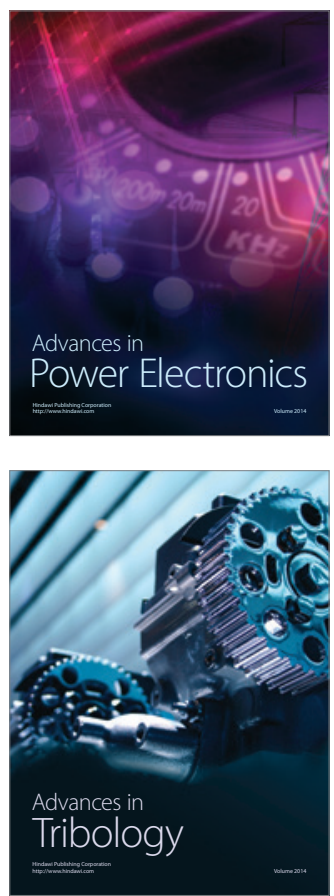

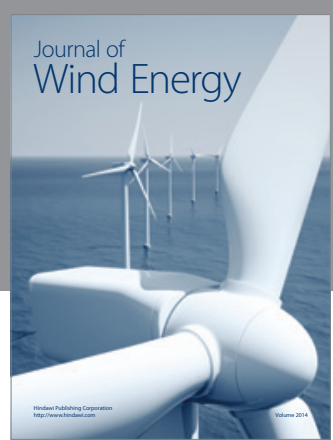

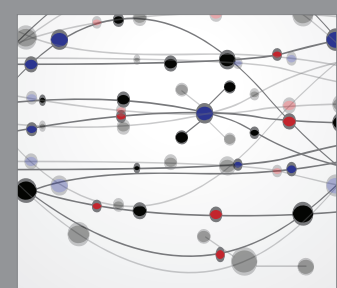

The Scientific World Journal

Submit your manuscripts at http://www.hindawi.com

Journal of

Structures
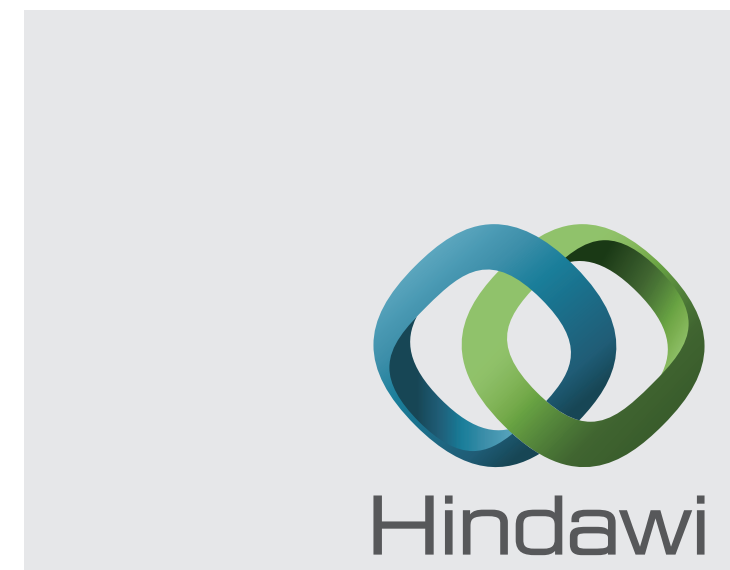

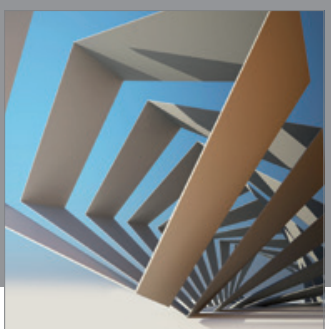

Rotating

Machinery
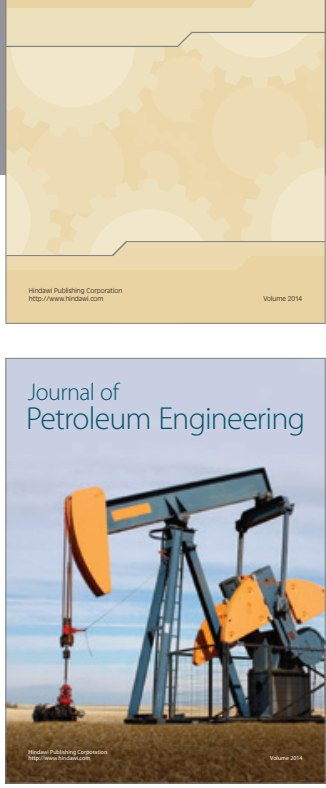

Journal of

Solar Energy
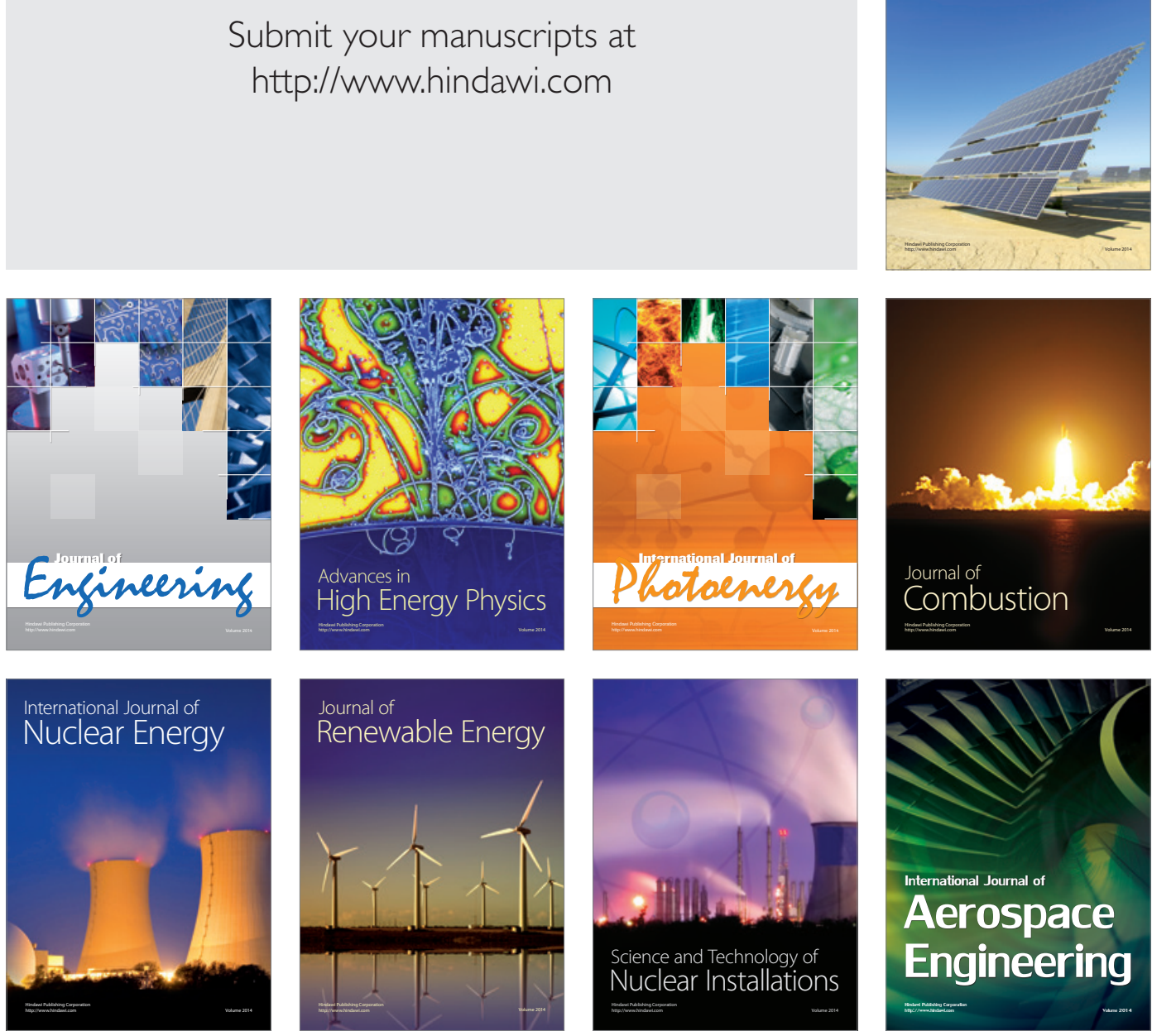